\title{
GÊNERO E DISCURSO: \\ CONSTRUÇÕES IDENTITÁRIAS DE UMA REFUGIADA
}

Jacqueline Teixeira*

\section{Resumo}

Este trabalho é um recorte da entrevista realizada com uma refugiada venezuelana que vive atualmente com sua família em um abrigo em Boa Vista - Roraima. A análise das estratégias e recursos discursivos utilizados por ela no encontro posiciona-a em um jogo de luz e sombra, no qual projeta o outro (esposo, ausente na interação) à luz, refratando o estereótipo do refugiado, e (des)constrói-se à sombra deste.

\section{Palavras-chave}

Discurso. Identidade. Interação. Gênero. Refúgio.

\section{1) Introdução}

Os dados que serão analisados neste trabalho fazem parte de uma pesquisa mais ampla realizada pela Cátedra Sérgio Vieira de Mello para refugiados da PUC-Rio, projeto multidisciplinar que agrega pesquisadores de diversas áreas com o objetivo de construir conhecimentos acerca da situação dos refugiados no Brasil. Esse projeto, em cooperação com a Agência da ONU para refugiados no Brasil (ACNUR), reúne diversas universidades que, "além de difundir o ensino universitário sobre temas relacionados ao refúgio, também visa promover a formação acadêmica e a capacitação de professores e estudantes dentro dessa temática", bem como "ações para fomentar o acesso e permanência ao ensino, a revalidação de diplomas e o ensino da língua portuguesa à população de refugiados", de acordo com o portal da ACNUR e da CSVM ${ }^{1}$.

Dentre os vários objetivos perseguidos pela Cátedra, destaco aquele cujo interesse repousa na análise das histórias contadas pelos próprios refugiados, a fim de investigar como suas identidades são construídas discursivamente, buscando entender, principalmente, a relação entre identidade e deslocamento/refúgio.

Em estudo recente, Megan Strom e Emily Alcock (2017) procuraram compreender, a partir da análise crítica do discurso, como a migração latina infantil era apresentada pela grande mídia nos Estados Unidos. Observaram que o uso recorrente de

\footnotetext{
* Jacqueline Teixeira, doutoranda no Programa de Pós-graduação em Estudos da Linguagem da Puc-Rio.

${ }^{1}$ Disponível em https://www.acnur.org/portugues/catedra-sergio-vieira-de-mello/
} 
formas metaforizadas da água como "onda ou inundação" para tratar do tema produz imediata associação a eventos negativos e incontroláveis, para os quais é necessário buscar uma solução rápida, independente, talvez, dos meios. Essa forma de representação não só fortalece as apresentações quantitativas, com seus números exorbitantes, como corrobora para a construção do migrante como aquele que precisa ser rejeitado, temido e detido. Abandonam-se as necessidades humanitárias, já que o perigo - o outro inimigo - é iminente. Ao tratar discursivamente a migração como uma forma de desastre ambiental, vidas são apagadas e histórias não são contadas.

Assumindo uma posição contrária ao exposto acima, este estudo nasce com a premissa de ouvir as "vozes do refúgio" e de colaborar com processos que humanizem esses Outros em situação de deslocamento forçado, rejeitando o silêncio dos fluxos, das ondas ou inundações que desumanizam e invisibilizam histórias de esperança.

\section{2) Questão central}

O deslocamento de pessoas, voluntária ou involuntariamente, foi marca recorrente no processo civilizatório desde os tempos mais remotos. Segundo Marques e Leal(2017), esse fenômeno tende a aumentar à proporção que a humanidade cresce, potencializando crises indistintas de natureza econômica, política ou social. Segundo a ONU, estamos assistindo na contemporaneidade a pior crise humanitária do século, sendo este também o de maior fluxo de refugiados desde a II Guerra Mundial, principalmente no continente europeu.

Essa crise também atinge a América Latina em virtude da difícil situação que atravessa a Venezuela. O cenário de instabilidades políticas, corrupção, desemprego, alta da inflação, recessão econômica, escassez de recursos básicos e violência leva milhares de venezuelanos a atravessar diariamente a fronteira com o Brasil, mais precisamente na cidade de Pacaraima - Roraima.

Os dados trazidos para análise vêm ratificar esses aspectos na voz de Angeli ${ }^{2}$, que nos conta as dificuldades de viver atualmente na Venezuela, com três filhas, tendo uma delas sérios problemas de saúde, sem emprego e sem dinheiro. Como ela mesma diz: "A Venezuela está destruída" - não restando outra saída senão se lançar à travessia da fronteira em busca de uma vida e um futuro melhores, principalmente para as filhas.

\footnotetext{
${ }^{2} \mathrm{O}$ nome apresentado é fictício, com o intuito de preservar a participante.
} 
A questão central desta análise foi investigar, pelas lentes discursivas e interacionais, a construção identitária da entrevistada em interação. O recorte analítico se deu pela recorrência de marcações generificadas no discurso da entrevistada e como estas auxiliam sua construção identitária.

Importante destacar que no áudio a entrevista ocorre em dois idiomas: o português utilizado pela pesquisadora e o espanhol, pela entrevistada, que concordou com o formato proposto. Contudo, para fins de transcrição, optou-se pela tradução espanhol/português ${ }^{3}$.

A seguir desenvolvo o quadro metodológico, seguido de um pequeno recorte teórico que alicerçará as análises que serão propostas e, por fim, a apresentação e a análise dos dados.

\section{3) Alguns aspectos metodológicos}

A análise proposta enquadra-se no paradigma qualitativo e interpretativista de pesquisa social (DENZIN e LINCOLN, 2006) por entender que todo conhecimento é perspectivado e situado. Portanto, não se alinha a uma pesquisa de significado universal e absoluto, ao contrário, reafirma o caráter provisório e parcial desse conhecimento, já que a realidade objetiva jamais pode ser captada integralmente.

Elegendo o micro como lócus de investigação, privilegia-se também uma abordagem interacionista (GUMPERZ, 1982; GOFFMAN, 2011; RIBEIRO e GARCEZ, 2013, entre outros) em que a atenção à fala em interação pode nos levar a compreender o que acontece no "aqui e agora" do evento comunicativo. Entendendo a entrevista como um encontro social como qualquer outro (MISHLER, 1986), na qual os significados são coconstruídos entre entrevistador e entrevistado, interessa-nos destacar e compreender como a experiência do refúgio é construída na voz de Angeli, bem como investigar a forma como ela vai construindo uma identidade generificada que reitera padrões sociais normativos e hegemônicos ao mesmo tempo em que refrata $o$ estereótipo de refugiado.

\section{4) Aspectos teóricos}

\footnotetext{
${ }^{3}$ A tradução foi realizada pela autora do artigo.
} 
Como suporte para o processo analítico, serão apresentadas de forma sucinta algumas reflexões teóricas de Goffman $(2002 ; 2011)$ acerca da interação e Deborah Cameron $(2006 ; 2010)$ no que diz respeito às questões de gênero, além de um pequeno recorte de estudos sobre gênero e refúgio.

\section{1) Interação}

Segundo Goffman ([1959]2002) alinhamento significa o posicionamento, a postura assumida pelo ator social ao apresentar-se, que deve estar em consonância com seu self, projeção do seu "eu” e ao discurso em construção na interação. Sendo esta uma atividade dinâmica, os alinhamentos podem ser negociados, ratificados ou não, cossustentados e modificados na interação. O alinhamento relaciona-se aos efeitos produzidos pelas elocuções, tanto na produção como na recepção destas, devido a mudanças de posturas ou posicionamentos dos atores.

Os encontros sociais regem e determinam a vida em sociedade. Esses encontros podem se dar face a face ou em contato mediado com outros participantes. Segundo Goffman, em cada um deles desempenhamos o que é chamado de linha, ou seja, um padrão de atos verbais e não verbais através dos quais expressamos nossa opinião sobre determinada situação. Para o autor, "não importa que a pessoa pretenda assumir uma linha ou não, ela sempre o fará na prática” (GOFFMAN, [1967]2011, p. 13).

Essa fundamentação teórica será relevante nos dados, uma vez que investigaremos a estratégia discursiva da pesquisadora para iniciar a entrevista, como forma de buscar o alinhamento com a entrevistada, assim como a linha discursiva assumida pela entrevistada ao longo da entrevista.

\section{2) Gênero}

Em uma perspectiva pós-estruturalista, gênero não é algo pré-discursivo, ou seja, é construído na interação com o outro através da linguagem, ratificado e publicizado a cada novo evento de forma situada, já que não existem identidades homogêneas e estáveis. Gênero, nessa visão, passa a ser considerado uma ação ou uma performance, e não um estado (BUTLER, 1990, apud SELL e OSTERMAN, 2009).

Segundo Cameron (2010, p. 132), essa nova perspectiva altera substancialmente o "foco de catalogação de diferenças entre homens e mulheres para uma pergunta mais 
sutil sobre como as pessoas usam recursos linguísticos para produzir a diferença de gênero.” Nesse questionamento, ela refuta o modelo de déficit proposto por Lakoff ${ }^{4}$, por estabelecer uma relação fixa entre forma e função na linguagem feminina. Também se distancia do modelo da diferença defendido por Tannen (2010), que acredita que homens e mulheres socializam-se de formas diferentes desde a infância. A esses modelos, Cameron (2010) contrapõe o da dominância, em que se observam não diferenças ou déficits, mas estruturas de poder nas quais gênero e linguagem estão imbricados. De acordo com a autora, enquanto produtores e agentes ativos, ao invés de reprodutores passivos de comportamentos generificados, homens e mulheres podem subverter os padrões de feminilidade e masculinidade a fim de produzir, de forma consciente, uma grande quantidade de efeitos e variações. Para Cameron:

\begin{abstract}
Nenhuma feminista contestaria que as mulheres são um grupo subordinado; mas grupos subordinados, afinal, negociam e lutam contra as condições de sua opressão. Certos aspectos do seu comportamento social podem ser proveitosamente analisados não como uma demonstração simples dessas condições, mas como maneira complexa de lidar com eles, ou mesmo um modo de resistência a eles (2006, p. 42).
\end{abstract}

A pergunta que fica após essa reflexão é "por que Angeli, nossa entrevistada, reforça um padrão generificado? Haveria nesse padrão alguma resistência?

\title{
4.3) Gênero e refúgio
}

Atualmente, alguns estudos (SCHWINN e COSTA, 2016; ABREU, 2018; PEÇANHA, ROSABONI e FERNANDES, 2018, entre outros) vêm se debruçando sobre as questões que envolvem gênero e refúgio, salientando que na grande maioria dos países de origem dos refugiados há uma hegemonia masculina.

Outro aspecto relevante é a ausência de legislação e de políticas que protejam as mulheres, vítimas vulneráveis da violência por motivo de gênero. Segundo esses estudos, as questões de gênero ainda são secundárias, pois o Estatuto do Refugiado em seu artigo $1^{\circ}$ apenas prevê cinco razões (temor de perseguição por motivo de raça,

\footnotetext{
${ }^{4}$ Para Lakoff existiria um modelo específico de fala feminina e de fala masculina. Em suas pesquisas, $\mathrm{O}$ autor estabelece padrões fixos de comportamento linguístico para os gêneros, tomados numa perspectiva essencialista. Ao tomar a fala masculina como padrão, reconhece déficits ou problemas na fala feminina. (CAMERON, 2006, p.33- 42).
} 
religião, nacionalidade, grupo social ou opinião políticas) ${ }^{5}$ para o consentimento de refúgio, silenciando outras sofridas e não menos importantes que afetam mulheres e LGBTQIs como a violência, o abuso e a perseguição sexual.

Além disso, essas pesquisas apontam para o fato de as mulheres serem tidas como agentes passivos dos processos migratórios e não como atores sociais (MORALES, 2007, apud SCHWINN e COSTA, 2016), devido ao estereótipo de dependência da figura masculina e de seu papel de esposa e mãe. Tal perspectiva generificada de refugiada pode ser verificada no posicionamento assumido por Angeli na entrevista. Dentre os motivos elencados por Morales (2007 apud SCHWINN e COSTA, 2016) para as migrações femininas, estão a reunificação familiar, a busca por trabalho, melhores condições econômicas e profissionais, a violência doméstica, dentre outros.

Cumpre ressaltar que, de acordo com Araujo (2013, apud SCHWINN e COSTA, 2016), embora exista um sistema internacional de proteção e ratificação de vários tratados por parte de diferentes países, esses instrumentos ainda não foram suficientes para eliminar a discriminação e garantir a igualdade de gênero.

Seria esse o motivo que leva nossa entrevistada a performar uma identidade generificada, pouco agentiva, valorizando os aspectos de masculinidade imputados socialmente aos homens e negado às mulheres, principalmente em situação de refúgio?

\section{4) Reflexão sobre os dados}

O recorte analítico privilegiou os momentos interacionais em que a entrevistada apresentou discursivamente construções generificadas.

Durante toda a entrevista, a conexão entre estas duas mulheres - pesquisadora e refugiada -, aspecto bastante característico em conversas femininas, segundo pesquisas na área (TANNEN, 2010, CAMERON, 2010 entre outras), pôde ser observada. As sobreposições ou interrupções de fala foram sempre cooperativas, utilizadas como auxílio à elaboração do tópico conversacional, sinalizando acolhimento tanto por parte da pesquisadora como da entrevistada.

\footnotetext{
5 A Declaração de Cartagena (1984) ampliou o alcance normativo para a concessão de refúgio: [...] as pessoas que tenham fugido dos seus países porque sua vida, segurança ou liberdade tenham sido ameaçadas pela violência generalizada, a agressão estrangeira, os conflitos internos, a violação maciça dos direitos humanos ou outras circunstâncias que tenham perturbado gravemente a ordem pública. Disponível em: https://www.acnur.org/fileadmin/Documentos/portugues/BD_Legal/Instrumentos_Internacionais/Declara cao_de_Cartagena.pdf. Acessado em 20 de jun. de 2019.
} 
No primeiro excerto podemos observar a forma delicada e preocupada com que a pesquisadora aborda o tema motivador da entrevista: o refúgio e a chegada ao Brasil. Já neste primeiro momento da interação, o esposo é trazido por Angeli como o precursor do deslocamento da família. O destaque dado a seu esposo será uma marca frequente no discurso e narração da entrevistada.

\section{Excerto 1}

\begin{tabular}{|c|c|c|}
\hline 1 & pesquis & se você puder contar um pouco da sua históbria \\
\hline 2 & & enfim e dos venezuelanos que você conhece só \\
\hline 3 & & pra gente tentar...humanizar um pouco e e... \\
\hline 4 & & olhar pra essas histórias [... individuais] \\
\hline 5 & Angeli & $\begin{array}{ll}\text { hum }] \\
\end{array}$ \\
\hline 6 & pesquis & também, porque a gente fala muito [nos fluxos] \\
\hline 7 & Angeli & {$[\mathrm{sim}]$} \\
\hline 8 & pesquis & nos números, né, mas a gente não fala muito \\
\hline 9 & & das histórias... particulares individuais das \\
\hline 10 & & pessoas. então... quando é que você veio pra \\
\hline 11 & & cá? faz quanto tempo que você tá aqui? \\
\hline 12 & Angeli & meu esposo está vindo para cá desde janeiro \\
\hline 13 & pesquis & Janeiro \\
\hline 14 & Angeli & e...ele ia e voltava porque as ( \\
\hline 15 & & estavam estudando. Eu tenho três filhas \\
\hline 16 & pesquis & três filhas. elas estão aqui? \\
\hline 17 & Angeli & já. e...então ele sempre ia e regressava \\
\hline 18 & & ia e regressava. quando se podia ( ) ele me \\
\hline 19 & & mandava dinheiro \\
\hline & $(\ldots)$ & \\
\hline & & \\
\hline & & \\
\hline & & \\
\hline 25 & & vim tem um mês e meio. \\
\hline
\end{tabular}

Ao iniciar a interação, a pesquisadora, linhas 1 a 4; 8 a 10, introduz um longo turno, justificando o motivo de sua pesquisa. Observam-se várias pausas em sua fala, linhas 3, 4, 9 e 10, o que pode significar certo desconforto diante da entrevistada, por saber, talvez, que sua solicitação traria histórias difíceis e doloridas de serem contadas. A postura cuidadosa da pesquisadora é compreendida por Angeli que, na linha 7, realiza uma sobreposição assertiva, "sim”, concordando com tal justificativa e com o sentido construído pela pesquisadora.

Ao tomar o turno na linha 12, Angeli elabora sua resposta em atendimento à solicitação da pesfquisadora, “meu esposo está vindo pra cá desde janeiro”. Pode-se observar que Angeli não apresenta a sua chegada, mas a de seu esposo. Obviamente, a

\footnotetext{
${ }^{6}$ Utilizou-se na transcrição da entrevista as convenções adaptadas da Análise da Conversa, anexada ao final do artigo.
} 
vinda de seu esposo marca o início do deslocamento da família, já que ela precisou ficar na Venezuela por causa da escola de suas três filhas. Além disso, a tomada de decisão de abandonar o país e seguir para outro na tentativa de melhores condições de vida não é algo de fácil ou rápida efetivação. Mas, o que desperta a atenção é como Angeli vai usando o agenciamento de seu esposo como marca em suas narrativas, performando e reproduzindo em seu discurso uma identidade de gênero hegemônica, ao empoderar e valorizar mais as ações do esposo que as próprias. Só apenas ao final do excerto (uma pequena parte não foi transcrita por não ser útil à análise conduzida no momento) é que Angeli relata há quanto tempo chegou ao Brasil.

No próximo excerto, observaremos mais um momento da interação em que a entrevistada, em continuação à sequência anterior, explica que a questão de saúde de uma das filhas foi decisiva para o abandono do país, devido à falta de condições para tratá-la, pois seu esposo não recebia mais pagamento em seu emprego. Discursivamente, Angeli reitera representações hegemônicas dos gêneros feminino e masculino, nas quais cabe à mulher o papel de cuidadora do lar e ao homem, de provedor da família. Não estamos com isso tecendo avaliações negativas quanto ao seu posicionamento, apenas procuramos compreender como essa mulher se constrói em seu discurso e a ele vincula subjetividades, visões e representações do mundo social. Como Goffman (2011) sugere, há uma ordem social que se desdobra na ordem interacional, possibilitando a interrelação entre os micros e macros discursos, pois é na superfície da fala em interação que componentes subjetivos e culturais, bem como as relações de poder são atualizadas. $\mathrm{O}$ autor defende uma sociologia das ocasiões, na qual "a organização social é o tema central, mas aquilo que é organizado é a mescla entre pessoas e as atividades interacionais temporárias que podem surgir a partir disso" (GOFFMAN, [1967] 2011, p. $10)$.

Partindo da defesa de Goffman para a existência de uma "sociologia das ocasiões", e sendo esta "a mescla entre pessoas e as atividades interacionais temporárias", o que nos garante que essa ocasião, ou seja, um encontro social entre duas mulheres, estando uma delas em situação de deslocamento forçado, não potencialize no discurso de Angeli padrões de gênero pautados pela diferença quanto aos papéis masculinos e femininos? Em situação de refúgio, o que pode ou deve ser dito por uma mulher? Seu alinhamento a um discurso normativo de gênero e de família parece cumprir duas funções: a de proteção do grupo familiar através da dependência e a de resistência aos estereótipos veiculados a indivíduos em situação diaspórica. 


\section{Excerto 2}

\begin{tabular}{|l|l|l|}
\hline 26 & Angeli & porque não havia dinheiro...ele trabalhava na \\
\hline 27 & & companhia, mas já não estava recebendo \\
\hline 28 & & pagamento igual e... \\
\hline 29 & Pesquis & pararam de te pagar lá? \\
\hline 30 & Angeli & Sim \\
\hline 31 & Pesquis & Sim \\
\hline 32 & Angeli & não havia transporte para via[jar] e aí ele \\
\hline 33 & pesquis & [sim] \\
\hline 34 & Angeli & ficava e não sabíamos se eu vinha. ele ficava \\
\hline 35 & & no trabalho e não sabia se voltava para casa. \\
\hline 36 & & era um pouco mais complicado \\
\hline
\end{tabular}

Embora Angeli apresente em sua narrativa a dificuldade de seu marido para prover as necessidades da família por falta de dinheiro, a pesquisadora, na linhas 29, elabora uma pergunta para checar a compreensão do que fora dito pela entrevistada “pararam de te pagar?”, obtendo uma resposta afirmativa por parte de Angeli. Percebemos, inicialmente, uma alteração de sentido, pois a pesquisadora reorienta o complemento do verbo "pagar" de "ele" (o marido) para "te" (a entrevistada). Ao responder afirmativamente, Angeli assume a reorientação proposta ou a ignora por não percebê-la? Podemos considerar que usos distintos de marcas de gênero no português e no espanhol atravessaram esse momento interacional. A não observação dessas marcas ${ }^{7}$ e o seu consequente abandono, tanto por parte da pesquisadora como da pesquisada, trazem para o primeiro plano a preocupação com a precariedade da sobrevivência, na qual ambos, marido e mulher, estão imbricados.

Em outro momento da entrevista, Angeli conta à pesquisadora que deseja sair de Roraima porque lá não vê futuro para as filhas e que todo empenho de ambos (Angeli e seu marido) está na busca por um bom futuro para elas. Acredita que o investimento na educação das meninas será fator essencial para que possam construir uma boa carreira profissional, em oposição à sua própria formação e condição, como se evidencia no próximo excerto, ao ser inquirida sobre sua formação escolar.

Mais uma vez observaremos que Angeli, ao mesmo tempo em que se (des) agencia, reorienta sua narrativa para a formação escolar e profissional de seu marido. Importante ressaltar que, ao colocar o marido sob a luz, também desconstrói o estereótipo de refugiado, ou seja, de pessoa dependente de ajuda externa, despreparado, e incapaz de sobrevivência autônoma. No caso, o marido de Angeli, na tentativa de continuar provendo a família que ficara na Venezuela até aquele momento, atravessa a

\footnotetext{
${ }^{7}$ A proximidade sonora do pronome pessoal reto no espanhol "el" (ele) e o pronome pessoal reto "eu" no português pode ter concorrido para a alteração de sentido.
} 
fronteira para buscar qualquer forma de trabalho e sustento, já que em seu país não era mais possível, mesmo com toda sua formação e seu preparo profissional, como será descrito por ela no excerto 3 :

\section{Excerto 3}

\begin{tabular}{|l|l|l|}
\hline 38 & pesquis & e você tinha estudado até onde na venezuela? \\
\hline 39 & Angeli & $($ ) \\
\hline 40 & pesquis & até que série, até que ano da escola? \\
\hline 41 & Angeli & EU? \\
\hline 42 & pesquis & Sim \\
\hline 43 & Angeli & até terceiro ano \\
\hline 44 & pesquis & \multicolumn{1}{|c|}{ terceiro ano } \\
\hline 45 & Angeli & \multicolumn{1}{|c|}{ e meu esposo( ${ }^{8}$} \\
\hline 46 & pesquis & Sim \\
\hline 47 & Angeli & mas ele trabalhava já em PDVSA de de mecânico \\
\hline 48 & & de máquinas pesadas, grandes \\
\hline 49 & pesquis & \multicolumn{1}{|c|}{} \\
\hline 50 & Angeli & e ficou dez anos trabalhando, dez anos e não \\
\hline 51 & & lhe quiseram dar a sua renúncia porque não \\
\hline 52 & & estão aceitando demissão para que não se evada \\
\hline 53 & & do país só que ele abandonou o cargo \\
\hline 54 & pesquis & sim, abandonou sem [direitos \\
\hline 55 & Angeli & \multicolumn{2}{|c|}{ [sim sim } \\
\hline
\end{tabular}

Note-se que, ao ser mais uma vez colocada no centro da questão pela pesquisadora, Angeli, na linha 41, busca confirmação da pergunta feita "EU?" de forma bastante intensa, conforme sugere a transcrição em caixa alta. Como se preferisse manter-se invisibilizada, apresenta imediatamente a formação de seu companheiro. Embora não tenha ficado compreensível na gravação qual a escolaridade do marido, o conectivo "mas" utilizado por ela (linha 47) para introduzir a atuação profissional de seu esposo parece querer nos dizer sobre a expertise e o potencial deste, apesar da pouca formação. É como se somente a história do companheiro tivesse valor ou fosse merecedora de ser narrada; a sua está sempre à sombra da do marido e de um projeto familiar, reiterando as diferenças entre os papéis sociais do homem e da mulher, bem como valorizando aquele em detrimento deste. Entretanto, não podemos mensurar até que ponto o contexto da pesquisa - uma família em deslocamento forçado - pode favorecer a construção de uma identidade feminina mais vulnerável e dependente para si em contraste à de seu marido, que é desenhado por ela discursivamente dentro de alguns padrões de masculinidade, tais como: trabalhador, provedor, agentivo, bom marido e

\footnotetext{
${ }^{8}$ Embora a compreensão de um trecho da entrevista tenha ficado comprometida, acredita-se não haver prejuízos para a análise proposta.
} 
bom pai. A ênfase de Angeli em um modelo tradicional e hegemônico de família parece expressar conforto e orgulho, além de garantir que suas declarações em uma entrevista, embora consentida, possam expor sua família dentro de padrões sociais aceitáveis e adequados.

Na sequência da entrevista, a pesquisadora pergunta se eles desejariam retornar à Venezuela em algum momento, pois lá deixaram alguns familiares (outros já estão no Peru, destino preferido e desejado por Angeli e o marido). Nesse momento, Angeli fica sob forte emoção e é acolhida gentilmente pela pesquisadora, que se solidariza à dor e ao sofrimento visível da entrevistada, ao relatar que não voltariam mais a seu país de origem.

Os dois próximos excertos são desdobramentos da pergunta sobre o regresso à Venezuela. O primeiro, excerto 4, apresenta outro discurso generificado de Angeli ao destacar seu apego à família em oposição ao desapego do marido:

\section{Excerto 4}

\begin{tabular}{|l|l|l|}
\hline 56 & Angeli & meu esposo também tem sua mãe lá mas eu sou \\
\hline 57 & & mais apegada com minha família que ele, mais \\
\hline 58 & & desprendido, tá aqui pelas meninas pelas \\
\hline 59 & & meninas então ( ) ele tem cursos, sabe de \\
\hline 60 & & computador, de maquinária, de eletricidade, de \\
\hline 61 & muitas coisas \\
\hline
\end{tabular}

Como dito, Angeli reforça e contrapõe padrões masculinos e femininos hegemônicos, ou seja, como mulher dependente, mais apegada afetivamente à família em oposição ao homem desprendido, portanto, mais livre, associado à sua capacitação "ele tem cursos, sabe de computador, de maquinária, de eletricidade, de muitas coisas". Saber sobre "muitas coisas" não lhe garante necessariamente um trabalho que corresponda à sua formação. Todavia, sua força e capacidade para o trabalho é uma marca recorrente no discurso de Angeli que, de alguma maneira, acaba por refratar, também, o estereótipo de refugiado.

No último excerto, Angeli rompe com seu padrão discursivo generificado, e apresenta-se na primeira pessoa do plural "batalhamos, vivemos, compramos nossas coisas...", linhas 65 a 67, ombreando com seu marido a construção da vida na Venezuela e a decisão de deixar tudo para trás: 


\section{Excerto 5}

\begin{tabular}{|l|l|l|}
\hline 62 & Angeli & tenho quinze anos de casada...com meu esposo \\
\hline 63 & pesquis & ele é voluntário daqui? \\
\hline 64 & Angeli & \multicolumn{1}{|c|}{ ele é voluntário também } \\
\hline 65 & & e...e nós batalhamos, vivemos, compramos nossa \\
\hline 66 & & casinha nossa coisas e temos que deixar tudo e \\
\hline 67 & & chegar aqui [sem nada \\
\hline 68 & pesquis & [sem nada \\
\hline 69 & Angeli & para ver se, pelas meninas porque temos três \\
\hline 70 & & filhas \\
\hline 71 & pesquis & Claro \\
\hline 72 & Angeli & aqui [ ( ) \\
\hline 73 & pesquis & [para sobreviver \\
\hline
\end{tabular}

Esse é o único momento em que a pesquisadora introduz uma pergunta direta sobre o marido na entrevista, participante ausente da interação, porém presente nas histórias e discursos da narradora, que, em vários momentos, subverteu o esperado falar de si - para apresentar-se a partir das experiências e predicativos de seu marido. É também nesse momento que Angeli apresenta-se não como coadjuvante passiva da história, mas como agente do processo, assumindo, em comunhão com o marido, o primeiro plano da ação (nós).

Mesmo nesse contexto, em que gênero e refúgio encontram-se tensionados, acentuando a assimetria entre os gêneros, abre-se no espaço interacional a possibilidade discursiva de reversão e suspensão desse padrão social e cultural. Como nos informa Cameron (2006), alguns aspectos do comportamento social podem ser analisados não apenas como "uma demonstração simples dessas condições, mas como maneira complexa de lidar com eles, ou mesmo de resistência a eles" (2006, p. 42). Nossa entrevistada, ao apresentar-se em conformidade com os padrões normatizados, ou mesmo quando rompe com eles discursivamente na interação, está lidando, a seu modo, com a difícil condição de mulher refugiada. A padronização de seu discurso, para além de marcações de gêneros, parece soar como forma de resistência à sua condição, bem como a de toda a famíli, na luta pela sobrevivência em condições tão adversas.

\section{5) Tentativa de possíveis costuras}

O presente trabalho procurou investigar como a entrevistada constrói sua identidade a partir de um discurso generificado, reproduzindo padrões normativos e hegemônicos de comportamentos femininos e masculinos. 
A recorrência em seu discurso dessas evidências destacou-se aos olhos da analista que, a todo instante, perguntava-se sobre o motivo dessa escolha. Obviamente, Angeli pode, por convicções subjetivas e opção individual, aderir a essa perspectiva social de papéis fixos e essencializados para homens e mulheres, assumindo para si um papel mais subalterno. Contudo, seu marido encontra-se tão vulnerável quanto ela, desprovido de alguns dos símbolos sociais de dominação masculina. Podemos inferir, talvez, que seja essa condição de desprestígio de seu marido que a leve a (re) valorizá-lo diante da pesquisadora. Apresentar um marido forte, agentivo, trabalhador, de boa formação profissional pode desempenhar duas funções: apresentar, sob sua ótica, o comportamento esperado e adequado de uma boa mulher e companheira, principalmente em situação de refúgio, como apontam alguns estudos sobre a desigualdade de gêneros nesse campo, como também desconstruir a imagem negativa do refugiado. Sendo mulher e refugiada, Angeli encontra-se duplamente vulnerável, podendo esse aspecto ter sido determinante para a forma como se (des) apresenta na entrevista e reforça estereótipos de masculinidade e feminilidade.

\section{Referências}

ABREU, Louise Leoni. Gênero e a Questão do Refúgio: as lacunas jurídicas de proteção à mulher refugiada. Cadernos de Relações Internacionais/PUC-Rio, Edição especial "Gênero e Sexualidade nas RI” Vol. 2 Setembro, 2018.

CAMERON, Deborah. On Language e sexual politics. Londres e Nova Iorque: Routledge - Taylor \& Francis Group, 2006.

Desempenhando identidade de gênero: conversa entre rapazes e construção da masculinidade heterossexual. In: OSTERMAN, Ana Cristina; FONTANA, Beatriz (Orgs.). Linguagem. Gênero. Sexualidade. Clássicos traduzidos, São Paulo: Parábola, 2010.

DENZIN, Norman K.; LINCOLN, Yvonna S. Introdução: a disciplina e a prática da pesquisa qualitativa. In: $O$ planejamento da pesquisa qualitativa: teorias e abordagens. Porto Alegre: Artmed Bookman, 2006.

GOFFMAN, Erving. A representação do eu na vida cotidiana. Rio de Janeiro: Vozes, [1959] 2002.

Ritual de interação. Rio de Janeiro: Vozes, [1967] 2011. 
GUMPERZ, John Joseph. Convenções de contextualização. In: RIBEIRO, Branca Telles e GARCEZ, Pedro M. (Orgs.). Sociolinguística interacional. São Paulo: Edições Loyola, [1982] 2013.

MARQUES, Andressa Clycia Mello de Souza; LEAL, Marilia Daniella Freitas Oliveira. Migrantes venezuelanos no Brasil: cooperação como meio de garantir direitos.

Disponível em

https://www.editorarealize.com.br/revistas/conidif/trabalhos/TRABALHO_EV082_MD 1_SA7_ID321_21082017230856.pdf. Acesso em dez. 2018.

MISHLER, Elliot G. Research interviewing. Context and narrative. Cambridge: Harvard University Press, 1986.

RIBEIRO, Branca Telles; GARCEZ, Pedro M. (Orgs.). Sociolinguística interacional. São Paulo: Edições Loyola, 2013.

PEÇANHA, Carolina Becker; ROSABONI, Karen Carvalho; FERNANDES, Maria Eduarda Santos Moury. Mulheres venezuelanas no estado de Roraima: desafios de proteção diante da necessidade de políticas públicas interseccionais.

Disponível em http://www.revistas2.uepg.br/index.php/sociais. Acesso em jan. 2019.

SCHWINN, Simone Andrea; COSTA, Marli Marlene Moraes da. Mulheres refugiadas e vulnerabilidade: a dimensão da violência de gênero em situações de refúgio e as estratégias do ACNUR no combate a essa violência. Revista Signos, Lajeado, ano 37, n. 2, 2016.

SELL, Mariléia; OSTERMAN, Ana Cristina. Análise de categorias de pertença (ACP) em estudos de linguagem e gênero: a (des)construção discursiva do homogêneo masculino. São Paulo: Alfa, 53 (1): 11-34, 2009.

STROM, Megan; ALCOCK, Emily. Floods, waves, and surges: the representation of Latin@ immigrant children in the United States mainstream media. Critical Discourse Studies, 2017.

Link do artigo: http://dx.doi.org/10.1080/17405904.2017.1284137

TANNEN, Deborah. Quem está interrompendo? Questões de dominação e controle. In: OSTERMAN, Ana Cristina; FONTANA, Beatriz (Orgs.). Linguagem. Gênero. Sexualidade. Clássicos traduzidos, São Paulo: Parábola, 2010.

GENDER AND DISCOURSE:

A REFUGEE'S IDENTITY CONSTRUCTIONS

Abstract: This paper analyses an excerpt from an interview with a Venezuelan refugee
who lives with her family in a shelter in Boa Vista - Roraima. The analysis of discursive
strategies and resources used by her in the meeting set up a game of light and shadow.
In this game, she projects the other (her husband, who is absent from the interaction) in 
the spotlight as an agent who refracts the stereotype of a refugee, while she herself is relegated to the shadows.

Keywords: Discourse. Identity. Interaction. Refuge.

\section{Anexo}

\section{Convenções de transcrição}

\begin{tabular}{|c|c|}
\hline ... & pausa não medida \\
\hline & entonação descendente ou final de elocução \\
\hline ? & entonação ascendente \\
\hline & entonação de continuidade \\
\hline & parada súbita \\
\hline & elocuções contíguas, enunciadas sem pausa entre elas \\
\hline sublinhado & ênfase \\
\hline IAIÚSCULA & fala em voz alta ou muita ênfase \\
\hline opalavra ${ }^{o}$ & palavra em voz baixa \\
\hline$>$ palavra $<$ & fala mais rápida \\
\hline palavra> & fala mais lenta \\
\hline ou :: & alongamentos \\
\hline & início de sobreposição de falas \\
\hline & final de sobreposição de falas \\
\hline ) & fala não compreendida \\
\hline )) & comentário do analista, descrição de atividade não verbal \\
\hline "palavra" & fala relatada, reconstrução de um diálogo \\
\hline & aspiração ou riso \\
\hline & subida de entonação \\
\hline & descida de entonação \\
\hline
\end{tabular}

Convenções baseadas nos estudos de Análise da Conversação (Sacks, Schegloff e Jefferson, 1974), incorporando símbolos sugeridos por Schifrin (1987) e Tannen (1989). 